\section{Walking and Sleep Quality of Nepalese Older Adults Resid- ing in an Old Age Home}

\author{
Hom Nath Chalise ${ }^{1,2 *}$ and Umanath Lamsal ${ }^{3}$ \\ ${ }^{1}$ Population Association of Nepal, Kathamandu, Nepal \\ ${ }^{2}$ Central Department of Population Studies, Tribhuvan University, Nepal \\ ${ }^{3}$ Sanothimi Campus, Tribhuvan University, Nepal
}

\begin{abstract}
Sleep disturbances are common among older adults. The objective of this study is to determine whether the activity of inside walking by older individuals residing in the old age home improves the quality of their sleep. Pashupati Briddhaashram (old age home) from Kathmandu is the facility selected for this study. This study uses a prepost quasi-experimental design of 36 older individuals who voluntarily participated utilizing the Pittsburgh Sleep Quality Index (PSQI) to measure the quality of individuals' sleep. In this program older residents walked three times per week for four weeks with the researchers or other assigned Briddhaashram Officers. Results show that after one months of walking, the Global PSQI score changes from 331 to 274 . This statistically significant result shows that walking is sufficient to improve the nighttime sleep quality of the participants. Moreover, nighttime sleep quality improved regardless of gender. Further analysis of several PSQI components shows that sleep latency, sleep duration, subjective sleep quality, habitual sleep efficiency and sleep disturbance were also found to improve significantly. These findings cannot be generalized to whole population, further in depth study in a large sample size with control group is required.
\end{abstract}

Keywords: Elderly; Physical activity; PSQI; Sleep quality; Walking

\section{Introduction}

There is no universal way of defining when a person becomes old. Factors like biological, psychological, chronological and social play an important role when a person is considered old. For all practical purposes, 60 years old is considered as a cutoff point to refer to the older population in developing countries [1]. Changes in physical, mental

*Corresponding author: Hom Nath Chalise, Central Department of Population Studies, Tribhuvan University, Kathamandu, Nepal, Tel: +977 9851012622 E-mail: chalisehkpp@gmail.com

Citation: Chalise HN, Lamsal U (2017) Walking and Sleep Quality of Nepalese Older Adults Residing in an Old Age Home. J Gerontol Geriatr Med 3: 016.

Received: April 15, 2017; Accepted: July 17, 2017; Published: July 31, 2017

Copyright: (c) 2017 Chalise HN and Lamsal U. This is an open-access article distributed under the terms of the Creative Commons Attribution License, which permits unrestricted use, distribution, and reproduction in any medium, provided the original author and source are credited. and social aspects is experienced as people age [2]. One such a change is seen on the quality of sleep [3]. Changes in sleep duration, pattern and quality differ with age [4]. These changes in sleep patterns are reflected in the common sleep-related complaints of older adults, such as taking longer to fall asleep, waking more often and being sleepy during the day. Sleep disorders can result in tiredness, fatigue, depression, greater anxiety, irritability, pain sensitivity, muscle tremors, immunosuppressant and lack of daytime alertness $[5,6]$.

The prevalence of sleep disturbances increases with age. Studies show more than $50 \%$ of people over the age of 65 experience sleep disturbances $[7,8]$. Poor sleep quality also becomes common during old age $[9,10]$. Sleep disturbances and the occurrence of illnesses or death are highly correlated [11]. Physical inactivity has been identified as a risk factor leading to many chronic diseases. One study also demonstrates that greater physical activity is associated with longevity and an Improved Quality of Life (QOL) [12]. The importance of physical activity in older adults, however, has often been neglected and given a lower priority compared to physical activity in the general population. One study found physical activity can even lower the death rate in people aged seventy to eighty-five years [13].

Walking is an affordable physical activity for older adults. Very little is known about what types of walking improve sleep the most, how much walking is needed to improve sleep and what time of day is best for walking to improve sleep in people with insomnia. Walking is a convenient, inexpensive, safe and effective exercise that can be undertaken by almost all people, at almost any time and in almost any place [13]. Most people can walk. Individuals are generally not hurt by walking and walking has benefits for wellness. Piepkorn determined that as little as 30 minutes of walking may be sufficient to keep individuals moderately physically active [14]. Very little research is carried out focusing older adults of Nepal [15-17]. More than $80 \%$ of older individuals still live with their children and many who are not cared for by their children prefer to live in a Briddasharam (Homes for elderly) run by government, religious community or community people [18]. Therefore, the main objective of this study is to study whether the activity of walking inside the Briddashram by individuals who reside there will improve the quality of their sleep.

\section{Methods and Materials}

This is a quasi-experimental design study conducted in 2012 in Kathmandu. Sampling for this study included nearly 200 older individuals residing in the Pashupati Briddhaashram (Old age home) of Kathmandu. Permission for this research was obtained from the administrators of the Briddashram. Before starting the survey, a joint meeting was held with the chief of Briddashram and older adults living there. Older adults who were physically good to simple walking were invited during the meeting. We explained the objective of our research and our aim. We encouraged older adults to participate voluntarily explaining the benefits of walking in the group. There were all together 60 older adults participated in the preliminary meeting. In the early days nearly 43 older adults participated in the walking.

In this program older adults walked three times per week for four weeks with the researcher or other assigned Briddashram Officer. The speed and time spent in walking was increased, at a comfortable peace, 
- Page 2 of 4 •

to 30 minutes of walking. There was not any instrument to measure the intensity of walking. Older adults were free to stop walk at any time and right to decide whether or not to participate in this study. 7 participants dropped walking without any specific reason and when asked it was their voluntary reason and remaining 36 completed the walking experiment. 36 participants who completed the experiment are included in this study.

\section{Tools}

Face-to-face interviews utilizing the Pittsburgh Sleep Quality Index (PSQI) questionnaire that measures the quality of sleep with simple demographic questionnaire was used [19]. PSQI is already being used in many countries. The questionnaire was translated into Nepali by two English to Nepali translators and also back translated in english by other two persons to minimize the error in translating. It was also simply pretested in 10 older adults living in other Briddashram and Nepali translation was slightly revised. A quantitative method was used to analyze the data. This study used a frequency table and t-test to analyze the data. Data were further analyzed using SPSS software version 20. All participants gave verbal informed consent before starting the study which is found common in the other studies also where participants are illiterate $[17,20]$.

\section{Results}

\section{Description of participants}

The age of the participants ranged from 65 years to 86 years with a mean age of $75.2( \pm 8.5)$ years (Table 1). Distribution of age shows one third (33\%) of the respondents were in the age group 70-74 years, followed by 31 percent in the age group 75-79 years, nearly one fifth (19.4 $\%$ ) in the 65-69 years age group and nearly 17 percent in the age group 80 years and above. The majority of the respondents in this study were female (56\%). Marital status of respondents shows that a majority of those women (70\%) were widows, nearly one fifth (19.4\%) were married but not living with their spouse and only $5.6 \%$ were single/never married. Majority of the respondent's (83\%) were illiterate and only 17 percent of participants could read and write. Moreover, 50 percent of respondents felt like they were physically active.

\section{Walking and sleep quality measured by the PSQI}

This study uses a pre-post quasi-experimental design. Details of the PSQI score is shown in table 2. This study analyses the scores of 36 participants who completed this one month long walking experiment. Prior to the month of walking, all thirty-six participants had a combined global PSQI score of 331. After one month of walking, the combined global PSQI score was 274. This decrease in score means the overall sleep quality of participants improved by 20.3 percent (Table 2). Global PSQI score is the sum of seven components: subjective sleep quality, sleep latency (or the initiation of sleep), sleep duration, habitual sleep efficiency; sleep disturbance, use of sleep medicines and day time dysfunction. Analysis of global (overall) and each of the components of Global PSQI are shown in table 2 and table 3.

Subjective sleep quality shows the pre-walk score 62 which decreased to 53 in the post walk period. The decrease was by 14.5 percent. Similarly sleep latency decreased from 65 to 49 which was $24.6 \%$ improvement in sleep latency. Sleep duration was also reduced from 72 to 56 an improvement in 22.2 percent. Habitual sleep efficiency is also improved from 59 to 50 , an 11.9 percent improvement. Sleep disturbance also changed from 44 to 38 , a change of 13.6 percent. Day time dysfunction score also decreased from 12 to 10 , which is $16.7 \%$ change. Further paired sample test was carried out on the pre-walk

\begin{tabular}{|c|c|c|c|c|}
\hline Characteristics & Number & Percentage & Mean & Range \\
\hline \multicolumn{3}{|l|}{ Age (Years) } & $75.2( \pm 8.5)$ & $65-87$ \\
\hline $65-69$ & 7 & 19.4 & & \\
\hline $70-74$ & 12 & 33.3 & & \\
\hline $75-79$ & 11 & 30.6 & & \\
\hline $80+$ & 6 & 16.7 & & \\
\hline \multicolumn{5}{|l|}{ Sex } \\
\hline Male & 13 & 44.4 & & \\
\hline Female & 17 & 55.6 & & \\
\hline \multicolumn{5}{|l|}{ Marital Status } \\
\hline Widow/widower & 21 & 75.0 & & \\
\hline $\begin{array}{l}\text { Married but living } \\
\text { separately }\end{array}$ & 7 & 19.4 & & \\
\hline Never Married & 2 & 5.6 & & \\
\hline \multicolumn{5}{|l|}{ Literacy Status } \\
\hline Literate & 8 & 22.2 & & \\
\hline Illiterate & 28 & 77.8 & & \\
\hline
\end{tabular}

Table 1: General characteristics of respondents.

and post-walk comparison to determine whether the difference after guided walking was significant. The result is shown in detail in table 3. It shows Global PSQI score improved significantly and it was significant for both male and female (it is not shown here). Similarly out of seven components of Global PSQI, five components were found improved significantly. In this study sleep latency, sleep duration, subjective sleep quality, habitual sleep efficiency and sleep disturbance were found improved significantly. On the other hand there was not significant improvement in the sleep quality in use of sleep medicine and day time dysfunction.

Further, while analyzing the individual score of the participants out of 36 participants that walked for one month 26 participants had decreased the score compared to baseline study. In another word 72 percent of the participants had to some extent improvement in their sleep quality.

\section{Discussion}

With the increasing life expectancy ageing is a worldwide issue of importance and less active lifestyle has created a variety of physical, mental, social and economic problems [15,20-22]. Sleep disorder in old age is a very common phenomenon but it is not understood well whether it can be improved through simple physical activities like walking. This study found, after a month long walking activity baseline combined global PSQI score of 331 dropped to 274 . This decrease in PSQI score (by one fifth) was statistically significant showing one month's walking was improved the quality nightmare sleep of participants. It was significant for both male and female when calculated separately. A similar study carried out by Brightman shows decrease in PSQI score means walking was good for sleep but the result was not statistically significant [23]. His study carried out in Nepal also shows the result was not significant to improve sleep quality.

Further analyzing the seven components of PSQI scale sleep latency, sleep duration, subjective sleep quality, habitual sleep efficiency and sleep disturbance were found improved significantly. On the other hand there was not significant improvement in the sleep quality on two components use of sleep medicine and day time dysfunction. Similar to this study of Brightman shows sleep latency, sleep 


\begin{tabular}{|c|c|c|c|c|c|c|c|c|}
\hline \multirow{2}{*}{ Variables } & \multirow{2}{*}{$\begin{array}{c}\text { Global } \\
\text { PSQI }\end{array}$} & \multicolumn{7}{|c|}{ Components of Global PSQI } \\
\cline { 5 - 10 } & & $\begin{array}{c}\text { Subj. Sleep } \\
\text { Quality }\end{array}$ & Sleep Latency & Sleep Duration & $\begin{array}{c}\text { Habitual Sleep } \\
\text { Efficiency }\end{array}$ & $\begin{array}{c}\text { Sleep } \\
\text { Disturbance }\end{array}$ & $\begin{array}{c}\text { Use of Sleep } \\
\text { Meds }\end{array}$ & $\begin{array}{c}\text { Daytime } \\
\text { Dysfunction }\end{array}$ \\
\hline Pre-walk & 331 & 62 & 65 & 72 & 59 & 44 & 17 & 12 \\
\hline Post-walk & 274 & 53 & 49 & 56 & 50 & 38 & 16 & 10 \\
\hline Percent improvement & $20.3 \%$ & $14.5 \%$ & $24.6 \%$ & $22.2 \%$ & $11.9 \%$ & $13.6 \%$ & 5.9 & 16.7 \\
\hline $\begin{array}{c}\text { Paired sampled } \\
\text { correlation }\end{array}$ & 0.835 & 0.587 & 0.728 & 0.793 & 0.902 & 0.902 & 0.988 & 0.939 \\
\hline $\boldsymbol{P}$ & $0.001^{*}$ & $0.000^{*}$ & $0.000^{\star}$ & $0.003^{*}$ & $0.007^{\star}$ & $0.012^{\star}$ & 0.235 & 0.121 \\
\hline
\end{tabular}

Table 2: Pre and Post-walk global PSQI components score comparison.

* Components that improved significantly

\begin{tabular}{|c|c|c|c|c|c|c|c|}
\hline \multirow{3}{*}{ Variable } & \multicolumn{5}{|c|}{ Paired Difference } & \multirow{3}{*}{$\mathbf{t}$} & \multirow{3}{*}{$P$} \\
\hline & \multirow{2}{*}{ Mean } & \multirow{2}{*}{ St Deviation } & \multirow{2}{*}{ SE Mean } & \multicolumn{2}{|c|}{$95 \%$ Confidence Interval of Difference } & & \\
\hline & & & & Lower & Upper & & \\
\hline $\begin{array}{c}\text { Overall } \\
\text { PSQI }\end{array}$ & 1.6111 & 1.6950 & 0.2825 & 1.0376 & 2.1846 & 5.703 & $0.000^{*}$ \\
\hline Comp 1 & 0.25000 & 0.4392 & 0.0732 & 0.1014 & 0.3986 & 3.416 & $0.002^{*}$ \\
\hline Comp 2 & 0.4444 & 0.6522 & 0.1087 & 0.2238 & 0.6651 & 4.089 & $0.000^{*}$ \\
\hline Comp 3 & 0.4444 & 0.6522 & 0.1087 & 0.2238 & 0.6651 & 4.089 & $0.000^{*}$ \\
\hline Comp 4 & 0.1944 & 0.4014 & 0.6690 & 0.0586 & 0.3302 & 2.907 & $0.006^{*}$ \\
\hline Comp 5 & 0.1667 & 0.3780 & 0.0629 & 0.0388 & 0.2945 & 2.646 & $0.012^{*}$ \\
\hline Comp 6 & 0.2778 & 0.1667 & 0.2778 & -0.0286 & 0.0842 & 1.000 & 0.324 \\
\hline Comp 7 & 0.5556 & 0.2323 & 0.0387 & -0.2305 & 0.1342 & 1.435 & 0.160 \\
\hline
\end{tabular}

Table 3: Paired samples test of different components of PSQI scale, Pashupatibriddashram.

${ }^{*}$ Components that improved significantly; Comp 1 = Subjective sleep quality, Comp 2 = Sleep latency, Comp 3= Sleep duration, Comp 4 = Habitual Sleep Effiency, Comp 5 = Sleep disturbance, Comp 6 = Use of sleep medicine and Comp 7 = Daytime dysfunction.

duration and sleep disturbance improved significantly [23]. Thus, for this particular sample, causal walking in the area inside the Pashupati Briddashram three times per week for one month significantly improved the participants' self-perceived aggregate sleep quality scores. Therefore, this research confirms the results of previous research [2429] that indicates walking improves nighttime sleep quality for older adults. Further, this result is consistent with the study of Ferris et al., [30] King et al., and Elavsky et al., that supported the effectiveness of physical activity on quality of sleep [30-32]. In addition, Rahmaninia et al., reported that a walking program of 8 weeks was effective in improving the quality of sleep of the older adults [33].

\section{Limitations}

There are some considerations that may have constituted limitations in this research. These factors might have limited the possible inferences that can be made from these results. First, this is one time quasi experimental study and causality cannot be assumed. Second, participants were not selected randomly and each volunteer participant was their own control. Third, the use of this pre-post quasi-experimental design may affect the results and influenced the ability to make inferences to the greater population of older adults. Fourth, the sample size was not calculated using any standard sample size calculation formula. Fifth residents were not monitored at all times during the day time and there was not control group. They may have napped or been physically active on their own. So, it's difficult to say whether the actual change was from walking alone. Sixth, Face to face interview may have some biased while reporting their perception.

\section{Conclusion}

The findings of this research clearly show that walking improve nighttime sleep quality of older adults. This finding can't be generalized to whole population, further in-depth study in a large sample size is required with control group.

\section{Acknowledgement}

We would like to express our sincere gratitude to University Grant Commission, Sanothimi Bhaktapur for financial support to carry out this research.

\section{References}

1. WHO (2002) Proposed working definition of an older person in Africa for the MDS Project. WHO, Geneva, Switzerland.

2. Daglar G, Pinar SE, Sabanciogullari S, Kav S (2014) Sleep quality in the elderly either living at home or in a nursing home. Australian Journal of Advanced Nursing 31: 6-13.

3. Lindstrom V, Andersson K, Lintrup M, Holst G, Berglund J (2012) Prevalence of sleep problems and pain among the elderly in Sweden. J Nutr Health Aging 16: 180-183.

4. Göktaș K, Özkan I (2006) Sleep disorders in old Age. Türk Geriatri Dergisi 9: 226-233.

5. Pandi-Perumal SR, Seils LK, Kayumov L, Ralph MR, Lowe A, et al. (2002) Senescence, sleep, and circadian rhythms. Ageing Res Rev 1: 559-604.

6. Barthlen GM (2002) Sleep disorders. Obstructive sleep apnea syndrome, restless legs syndrome, and insomnia in geriatric patients. Geriatrics 57: 3439. 
7. Fadıloğlu Ç, İlkbay Y, Yıldırım YK (2006) Sleep quality in the nursing age. Türk Geriatri Dergisi 9: 165-169.

8. Zeitlhofer J, Schmeiser-Rieder A, Tribl G, Rosenberger A, Bolitschek J, et al (2000) Sleep and quality of life in the Austrian population. Acta Neurol Scand 102: $249-257$.

9. Ancoli-Israel S (2004) Sleep disorders in older adults. A primary care guide to assessing 4 common sleep problems in geriatric patients. Geriatrics 59: $37-40$.

10. Neubauer DN (1999) Sleep problems in the elderly. American Family Physician 59: 2551-2558.

11. Corrêa K, Ceolim MF (2008) Sleep quality in aged patients with peripheral vascular diseases. Revista da Escola de Enfermagem da USP 42.

12. Lam CT (2014) The effect of walking on quality of elderly people. Master of Public Health, The University of Hong Kong, Sandy Bay, Hong Kong.

13. Gingbold R (1992) Successful ageing. Oxford University Press, New York USA.

14. Piepkorn MB (1990) An examination of the motivational differences between adults in structured and unstructured exercise programs. Unpublished Thesis, Purdue University, USA.

15. Chalise HN (2014) Depression among elderly living in Briddashram (old age home). Advances in Aging Research 3: 6-11.

16. Chalise HN, Kai I, Saito T (2010) Social support and its correlation with loneliness: A cross-cultural study of Nepalese older adults. Int J Aging Hum Dev 71: 115-138.

17. Chalise HN, Saito T, Takahashi M, Kai I (2007) Relationship specialization amongst sources and receivers of social support and its correlations with loneliness and subjective well-being: a cross sectional study of Nepalese older adults. Arch Gerontol Geriatr 44: 299-314.

18. Chalise HN, Brightman JD (2006) Aging trends: Population aging in Nepal. Geriatrics \& Gerontology International 6: 199-204.

19. Buysse DJ, Reynolds CF, Monk TH, Berman SR, Kupfer DJ (1989) The Pittsburgh Sleep Quality Index: a new instrument for psychiatric practice and research. Psychiatry Res 28: 193-213.

20. Chalise HN, Basnet $\mathrm{M}$ (2017) Abuse of older adults residing in the community of Nepal. J Gerontol Geriatr Res 6: 415.
21. Narang I, Manlhiot C, Davies-Shaw J, Gibson D, Chahal N, et al. (2012) Sleep disturbance and cardiovascular risk in adolescents. CMAJ 184: 913-920.

22. Asadnia S, Sepehrianazar F, Mosarrezaii Aghdam A, Saadatmand S (2013) Comparison of sleep quality and migraine headaches in people with proper and improper and poor sleep. Urmia Med J 23: 799-806.

23. Brightman JD (2012) Casual walking and nighttime sleep quality among older adults: Evidence from Kaneohe, Hawai'i utilizing the Pittsburgh Sleep Quality Index. University of Hawaii at Manoa, Honolulu, Hawaii.

24. Butler RN, Davis R, Lewis CB, Nelson ME, Strauss E (1998) Physical fitness: benefits of exercise for the older patient. 2. Geriatrics 53: 46-62.

25. King AC, Oman RF, Brassington GS, Bliwise DL, Haskell WL (1997) Moderate-intensity exercise and self-rated quality of sleep in older adults. A randomized controlled trial. JAMA 277: 32-37.

26. Kligman EW, Hewitt MJ, Crowell DL (1999) Recommending Exercise to Healthy Older Adults: The preparticipation evaluation and exercise prescription. The Physician and Sportsmedicine 27: 42-62.

27. [No authors listed] American College of Sports Medicine Position Stand. Exercise and physical activity for older adults. Med Sci Sports Exerc 30: 9921008.

28. O'Connor PJ, Youngstedt SD (1997) Sleep quality in elderly: Effects of exercise training and influence of sunlight exposure. JAMA 277: 1034-1035.

29. Pinkowish MD (1998) Exercise more, sleep better. Patient Care 32: 188

30. Ferris LT, Williams JS, Shen CL, Albus KA, Hale KB (2004) Resistance training improves sleep quality in older adults. Med Sci Sports Exerc 36: 287.

31. King AC, Pruitt LA, Woo S, Castro CM, Ahn DK, et al. (2008) Effects of moderate-intensity exercise on polysomnographic and subjective sleep quality in older adults with mild to moderate sleep complaints. J Gerontol A Biol Sci Med Sci 63: 997-1004.

32. Elavsky S, McAuley E (2007) Lack of perceived sleep improvement after 4-month structured exercise programs. Menopause 14: 535-540.

33. Rahmaninia F, Mohebi H, Saberian Brojeni M (2010) Effect of walking on quality, quantity and some physiological parameters related to sleep in old men. J Sport Bio Sci 1: 111-126. 